\title{
Editorial
}

\section{Hierarchy in World Politics}

Journal of International Relations and Development (2011) 14, 151-152. doi:10.1057/jird.2011.3

With this Special Issue the editorial team fulfils a campaign promise, so to speak. In our original proposal to assume the editorship of the Journal of International Relations and Development, we proposed three special features: a Forum on IR in Eastern and Central Europe (published in issue 12:2), a Forum on post-Communist and post-Socialist transitions (published in issue 12:4), and a Special Issue on hierarchy in world politics. The four papers collected here represent the end result of a process of soliciting proposals for manuscripts, putting those manuscripts through the regular peer-review process, and selecting papers that would allow a multi-faceted exploration of a complex topic that has made its way back into IR after the long interregnum of theories and models that focused on presumptively equivalent states operating under conditions of anarchy. But this is more than simply 'bringing hierarchy back in'; the new focus on unequal relations of power in world politics is a good deal more sophisticated than the sometimes blunt assertions of dependency theory and early world-systems accounts. The papers that we have assembled for this Special Issue represent some, but by no means all, of the rich analytical diversity in contemporary accounts of hierarchy in world politics.

We open the issue with Helge Jordheim and Iver Neumann's conceptual history of empire and imperialism, terms under which much of the contemporary analysis of hierarchy in world politics operates. Papers by Hugh Dyer and Ray Hinnebusch apply refined notions of imperialism to ecological politics and the Middle East, respectively, demonstrating some of the analytical productivity of thinking beyond the sovereign state in trying to grasp the character of present-day global politics. Miriam Prys and Stefan Robel close the issue with a challenge to the conceptual framework of imperialism, urging scholars to think in terms of hegemony rather than empire. Taken as a whole, these four papers illustrate the enormous theoretical and conceptual innovation going on in contemporary IR, once one sheds state-centric blinders and looks at more subtle and widespread forms of global power and influence; they also illustrate the power of an approach to the study of world politics that takes its cue from the traditions of historical sociology and critical historiography, rather than from marginalist economics and rationalist 
theories of bargaining. The resulting image of the world shows us a far more contingent and complex place than the familiar portrait of sovereign states interacting for mutual gain - but that complexity and contingency may give us critical insights that would otherwise remain unvoiced.

Patrick Thaddeus Jackson Editor-in-Chief

George Lawson Associate Editor 